\title{
A Review on Different Benefits of Mushroom
}

\author{
Dr.Romi Singh \\ School of Environmental Biology A.P.S.U. Rewa
}

\begin{abstract}
This paper reviews mushrooms. In this paper, nutritional and medicinal values, other uses of mushrooms were discussed. Mushrooms have been important in human history as food, as medicine, as legands, and in folk lore and religion. Mushrooms are basically consumed for their texture and flavor. They have recently become attractive as health - beneficent food and as sources for the development of drugs. Many higher mushrooms are known to contain a number of biologically active components that show promising antitumor and immunomodulating, cardiovascular, hepatoprotective, hypocholesterolemic, antiviral, antibacterial, antiparasitic and antidiabetic effects. Nutritional value of mushrooms lies between that of meat and vegetables. The rich source of proteins, vitamins and minerals and low in fat content (2-8\%) unique chemicals constitution of mushrooms makes them low calorie food 8 and choice diet for those suffering from hypertension, arthrosclerosis, diabetes, obesity. Mushrooms play a role in the development of new biological remediation techniques and filtration technologies (e.g. using fungi to lower bacterial levels in contaminated water). From the review it was observed that developing countries should harness the potentials of mushrooms as this would boost the revenue income and healthy living. It is hoped that this paper would add to existing information on this fungus.
\end{abstract}

Keywords: Mushrooms, Medicinal value, Nutritional value.

\section{Introduction}

Mushrooms are macro fungi with distinctive fruiting bodies which are either epigenous or hypogenous and sufficiently conspicuous to the naked eye to be hand-picked (Chang and Miles, 1982). Mushrooms are lively in folklore as ,witches egg and fairy egg' (Molitoris, 2001). The appraisal of mushrooms as highly nutritive foodstuff is well founded. Many kinds of mushrooms are edible, and at the same time possess tonic and medical attributes (Chang, 1999).Human use of mushrooms extent as early to $5000 \mathrm{BC}$. About 2000 species of edible mushrooms are known all over the world. For centuries, some mushrooms have been used in religious ceremonies of many ancient people and primitive tribes. Mushrooms are believed by the Romans to have properties that could produce super human strength, help in finding lost objects and lead the soul to the realm of the gods (Grube et al., 2001). Edible mushrooms are important sources of food. They form very nourishing meals especially for invalids, for they are easily digestible. They are consumed not only for their innate flavour and taste, but also for their important nutritional value. On fresh weight basis mushrooms are superior in protein content (Aremu et al., 2009) to all vegetables and fruits, but are inferior to meat and dairy products, which are the conventional protein sources. On dry-weight basis, however, mushrooms are similar with respect to driedyeast and superior to dried peas and beans.

Most mushroom derived preparation and substances find their use not as pharmaceutical but as a novel class of dietary supplements (DS) or ,nutraceutical ${ }^{\circ}$. A mushroom nutraceuticals is a refined or partially refined extract or dried biomass from either the mycelium or the fruiting body of the mushroom, which is consumed in the form of capsule or tablets as a dietary supplement and which may enhance the immune response of human body, thereby increasing resistance to disease and in some cases causing regression of a disease state (Wasser et al., 2000). Many pharmaceutical substances with potent and unique properties were isolated from mushroom and distributed worldwide (Wasser and Weis, 1999). Extensive clinical studies have explicitly illustrated that a number of mushroom species have medicinal and therapeutic value in the prevention /treatment of cancer, viral disease, hypercholesterolemia, blood platelet aggregation, and hypertension (Jong et al., 1991 etc. (Subramanian, 1995). Among the 14,000 species known, 2000 are safe and about 600 have significant pharmacological properties (Wasser et al., 2000). Most of the traditional knowledge about medicinal properties comes from the Far East (China, Japan, Korea, and Russia). Anticancer drugs isolated from mushrooms such as Lentinus edodus, Coriolus versicolor and Schizophyllum commune are sold in Japan (Jong and Birmingham, 1992). Medicines from poisonous mushrooms have been considered in China as "poison as an antidote for poison' (Yang and Jong, 1989).

Ita et al, (2008) in their study on bioaccumulation potential of heavy metals in sporocarps from Niger Delta region of Nigeria, revealed that certain mushrooms accumulate heavy metals. The accumulating potentials are affected by the species, substrate composition, age of mycelium and intervals between fructifications. Studies on metals in mushrooms have shown a correlation between fungal metals concentration and point 
sources of metal pollution (Isildak et al, 2004; Gyar and Ogbonna, 2006). Human activities have been reported to impact negativity on arable lands contaminating them with pesticides, petroleum hydrocarbons, heavy metals and waste engine oil pollutants, and consequently causing arable land shortage and other environmental challenges (Okhuoya et al, 2010; Oghenekaro et al, 2008). These challenges may exert negative effect such as kidney damage, impairment of circulatory, reproductive and nervous system damage (Abulude et al, 2004) on man and animals when consumed (Ita et al, 2008).Mushroom mycelia can produce a group of complex extracellular enzymes which can degrade and utilize the lignocelluloses wastes in order to reduce pollution. It has been revealed recently that mushroom mycelia can play a significant role in the restoration of damaged environments. Saprotrophic, endophytic, mycorrhizal, and even parasitic mushrooms can be performed in four different ways: mycofiltration (using mycelia to filter water), mycoforestry (using mycelia to restore forests), mycoremediation (using mycelia to eliminate toxic waste), and mycopesticides (using mycelia to control insect pests). These methods represent the potential to create a clean ecosystem, where no damage will be left after fungal implementation (Training Manual on Mushrooms cultivation, 2008).

\section{Nutritional Benefits}

Mushrooms are important sources of food. They are consumed not only for their innate flavor and taste, but also for their important nutritional value. The nutrient content varies from species and depends on their growth requirement. Mushrooms have a high percentage of water $93-95 \%$ as compared to learn beef (70\%) and fresh vegetables (92\%). They also contain valuable minerals such as iron, potassium, phosphorus, calcium and copper, $56 \%$ carbohydrate, $30 \%$ protein, $2 \%$ fat and also $10 \%$ ash on dry weight basis. They are also rich in vitamin B and vitamin D. Mushrooms provide a high protein and low caloric diet and can thus be recommended to heart patients. They also contain all the essential amino-acid required by an adult (Koyyalamudi et al., 2009). Mushrooms is reported to be an excellent source of riboflavin and nicotinic acid; a good source of pantothenic acid and ascorbic acid (Ukpebor et al., 2007). The absence of starch in mushrooms makes it an ideal food for diabetic patients and for persons who wants to shed excess fat. Kettawan et al., (2011) and Selvi et al (2007) have demonstrated that mushrooms contain antioxidants. Mushroom proteins contain all the essential amino acids and are especially rich in lysine and leucine, which are lacking in most staple cereal food. The low total fat content, and high proportion of polyunsaturated fatty acids (72-85\%) relative to total fatty acids, is considered a significant contribution to the health value to mushrooms. Fresh mushrooms contain relatively large amount of carbohydrate and further range from $51-88 \%$ and $4-20 \%$ mushroom appear to be a good source of vitamin including thiamine, riboflavin, niacin, biotin and ascorbic acid (Andrae et al., 1999). They can be successfully used as appetizers in marinated form and also as an ingredient in soups, sauces, salads, stuffing and meat dishes (Achremowicz et al., 1983). Mushrooms also contain many mineral salts and vitamins, particularly of the B and some D groups (Mattila et al., 2001). $100 \mathrm{~g}$ of fresh mushrooms contains 5.3-14.8 g of dry matter, 1.5-6.7 $\mathrm{g}$ of carbohydrates, 1.5-3.0 g of protein and 0.3-0.4 g of fat. Recently, Dundar et al. (2009) have made a comprehensive study of effect of various substrate on the chemical composition and nutritional values of P.ostreatus.

Mushrooms are non-photosynthetic organisms therefore, sugars, carbohydrates are present in lower proportions than vegetables such as carrots and sprouts, and so provide only a fraction of the energy requirement. There are about eight essential amino acids, that is, those which cannot be produced by the human body, and so must be consumed in the diet daily. Mushroom protein appears to be intermediate in nutritional qualities between meat and vegetable proteins. Some species like provide nutritive value comparable to that of meats and milk, but P.ostreatus due to low protein content, and deficiency in some essential amino acids has a low nutritive value (Bano and Rajarathnam, 1982).Apart from protein compounds, free amino acids, chitin, amines, nucleic acids and urea can also be found in mushrooms. Mushrooms like most vegetable are characteristically cholesterol-free food comprising of 2-8\% fat on dry weight basis. The crude fat includes representatives of all classes of lipid compounds including free fatty acids, glycerides, sterols, and phospholipids. Of existing fatty acids, a high proportion are linoleic acid (the only essential fatty acid required in the human diet), that constituting63-74\% of total fatty acids. Oyster mushrooms also possess bioactive compounds with hypocholesterolaemic activities, such as polysaccharides, mevinolin and other statins (GundeCimerman and Plemenitas, 2001). P.citrinopileatus fruiting body extracts have been shown to have antihyperlipidaemic effects that may lower serum triglyceride and cholesterol (Hu et al., 2006).

The fructifications of mushrooms are characterized by high levels of well assimilable mineral constituent (Mattila et al., 2001) whose level depends on the species and age of the mushrooms, the diameter of the pilei and on the substratum (Demirbas, 2001). There are many essential vitamins required daily in our diet. Mushrooms are important sources of vitamins especially of group B particularly thiamine, riboflavin, pyridoxine, pantothenic acid, nicotinic acid, nicotinamide, folic acid and cobalamine, other vitamins, such as ergosterol, biotin and tocopherols are also present (Mattila et al., 2001). Vegetarians are aware of that mushrooms are one of the best plant-based sources of niacin around the world and $100 \mathrm{~g}$ of fresh mushrooms 
provide more than a quarter of the adult daily requirement of this vitamin. Mushrooms are unique in that they contain vitamin B12, something that is not present in vegetables. Since B12 is mainly of animal origin, deficiency is commonly associated with vegetarian diets. Mushrooms were found to contain $0.32-0.65 \mathrm{mg}$ of $\mathrm{B} 12$ per $\mathrm{g}$, allowing just $3 \mathrm{~g}$ of fresh mushrooms to provide the RDA of this vitamin. Vegetarians may find this a useful way of getting this important nutrient. Vitamin A is uncommon although several mushrooms contain detectable amounts of pro-vitamin-A measured as the $\beta$-carotene equivalent. Most cultivated mushrooms are believed to contain low amounts of the fat soluble vitamins, $\mathrm{K}$ and $\mathrm{E}$, and only a small of vitamin $\mathrm{C}$

(Bernas et al. 2006).

\section{Medicinal Benefits}

A number of mushroom species are known to possess medicinal properties where Ganoderma, king of medicinal mushrooms, and Lentinula,are the most important genera (Chang, 1996). Lentinula edodes (shiitake), Grifola frondosa (maitake)have a history of medicinal use spanning millennia in parts of Asia. Medicinal mushroom research has indicated possible cardiovascular, anticancer, antiviral, antibacterial, antiparasitic, antiinflammatory, hepatoprotective, and antidiabetic activities (Lentinan, 2009). Amanita muscaria used therapeutically as a powder, tincture for swollen glands, nervous troubles and epilepsy etc. A lotion made out of this can be used externally and internally for the ailments of heart and inflammation of eye. Amanita phalloids is used against cholera and intermittent fever. Psilocybin and psilocin are two other drugs extracted from Psilocybe mexicana used to treat mental disorders (Bahl, 1987). Significant pharmacological effects or physiological properties of mushrooms are bioregulation (immunological enhancement), maintenance of homeostasis, and regulation of biorhythm, cure of various diseases and prevention and 10 improvement of life threatening diseases such as cancer, cerebral stroke and heart diseases. It is also confirmed that mushrooms have effective substances for antifungal, anti-inflammatory, antitumor, antiviral, antibacterial, hepatoprotective, antidiabetic, hypolipedemic, antithrombotic, hypotensive and other applications (Wasser and Weis, 1999). Antioxidant compounds prevent oxidative damage related to aging and diseases, such as atherosclerosis, diabetes, cancer and cirrhosis. Mushrooms that contain antioxidants or increase antioxidant enzyme activity may be used to reduce oxidative damage in humans (Yang et al., 2002).

Recently extracts from fruiting bodies and mycelia of Ganoderma species and Volvariella found to possess in vitro antioxidant activity (Jones and Janardhanan, 2000; Lakshmi et al., 2003; Mau et al., 2002; Mathew et al., 2008) and antimutagenic activities (Lakshmi et al., 2003). Oyster mushrooms (species of genus Pleurotus) are highly edible and nutritious, rank second among the commercially cultivated mushrooms in the world (Chang, 1999) and are demonstrated to possess antioxidant, anti-inflammatory and antitumor activities (Jose and Janardhanan, 2000. Currently, several extracts have wide spread use in Japan, Korea, and China, as adjuncts to radiation treatments and chemotherapy (Smith et al, 2002; Borchers et al, 2008). Mushrooms that have psychoactive substances have been used as sacraments for healing (Mental and physical) (Hudler 2000). Certain mushrooms, especially polypores like Reishi were thought to be able to benefit a wide variety of health ailments (Sarfaraz et al, 2009.).

Of 89 mushroom species tested, an extract from P.cornucopiae possessed the most effective antigenotoxic and bio-antimutagenic activities when tested on Salmonella typhimurium and Escherichia coli (Filipic et al., 2002). Oyster mushrooms possess bioactive compounds with hypocholesterolaemic activities, such as polysaccharides, mevinolin and other statins (Gunde-Cimerman and Plemenitas, 2001). It has recently been reported that P.citrinopileatus fruiting body extracts exerted antihyperlipidaemic effects. Antibacterial and antifungal activities have been observed in Pleurotus spp extracts and isolated compounds, presumably produced as a defense mechanism against other organisms (Ngai \& Ng, 2006).

\section{Other Benefits}

According to Wikipedia, the free encyclopedia (2011), mushrooms have been used for dyeing wood and other natural fibers. The chromosphores of mushroom dyes are organic compound and produce strong and vivid colors, and all colors of the spectrum can be achieved with mushrooms dyes. Dyes from them have been the source of many dyes before the synthetic ones (Mussak and Bechtold 2009). Presently, they play a role in the development of new biological remediation techniques and filtration technologies (Wikipedia, 2011).In the US, and other developed countries, mushrooms have been used as fire starters.The increased agro-industrial activities have led to the accumulation of a large quantity of lignocellulosic residues and many agro-chemicals all over the world. Many of Pleurotus species are primary decomposers of hardwood trees and are found worldwide. Due to presence of non specific oxygenases they are being used in the in situ degradation of many xenobiotics, phenolics, colouring pigments in effluents etc. Amaral et al. (2004) also reported the use of $T$. versicolor as biocatalysts for decolorization of different industrial dyes and waste water treatments. Recent studies have shown that $P$. ostreatusis able to degrade a variety of polycyclic aromatic hydrocarbon (Sack and Gunthen, 1993). 
Right from harvesting, processing and consumption of agricultural products a huge quantity of agrowastes are generated which often create disposal problem. Besides cereal and other crop wastes agro-industrial units also produce huge quantities of wastes e.g. Rice straw although it is used in the feeding of ruminants, it has a very low protein content and low digestibility. It is now well accepted that some mushrooms, particularly some species of Pleurotus has the ability to upgrade cattle feed by colonizing different types of crop/vegetable wastes thereby increasing their digestibility through delignification (Rajarathnam et al., 1992, Adamovic et al., 1998 \& Salmones et al., 2005).Laccase is an extracellular phenol oxidase produced by many mushrooms and has an important role in lignin biodegradation (Higuchi, $1990 \&$ Sanjdr and Baldrian, 2007). The ability of Pleurotus spp for the bioconversion of agro-wastes is due to the presence of non-specific oxygenases, are also being explored in bioremediation efforts. This includes degradation of chlorinated mono-aromatics (Buswell, 2001), as well as in the biodegradation of other xenobiotic compounds (Morgan et al.,1991), in the purification of air, water and soil, in the cleanup of contaminated soils and in the treatment of industrial effluents (Reid et al.,2002).Another application is the biodegradation of industrial effluents such as dyes. The possible risk to humans that ingest food containing dyes can be extended to the environment, for factories discharge their residues into nearby rivers and streams. P.florida has been in the degradation of dyes, a possible alternative in the treatment of industrial effluents (Espindola et al., 2007) Trametes versicolor produced three lignolytic enzymes with efficient degradation capacity on lignin, polycyclic aromatic hydrocarbons, polychlorinated biphenyl mixture and a number of synthetic dyes (Tanaka et al., 1999; Novotny et al., 2004). T. versicolor and its enzymes have been reported to delignify and to bleach kraft pulp (Gamelas et al., 2005) and also efficiently dechlorinate and decolorize bleach kraft pulp effluents (Selvam et al., 2002). This presents a good potential to be the base of new environmental friendly technologies for pulp and paper industry. Emuh (2010) reported that the crude oil and heavy metals present in polluted soil are broken down and absorbed by mushroom hypha and mycelia through the secretion of enzymes into environmentally safe levels resulting in carbon (IV) oxide, water and perhaps biomass. Zebulun et al. (2011) worked on the decontamination of anthracene-polluted soil through a mushroom ( $P$. ostreatus) induced biodegradation. They reported that time, level of contamination and fungal treatment affected the rate of degradation of all levels of anthracene degradation (76 to 89\%) compared to control soil (33 to $51 \%)$.

Pleurotus spp are potential candidates for the production of industrially important enzymes using cheap raw materials like agro-waste. The $P$. tuber-regium is anothermushroom examined for its ability to ameliorate crude oil polluted soil. Isikhuemhen et al. (2003) reported that the mushroom had the ability to ameliorate crude oil polluted soil and the resulting soil sample supported seed germination and seedling growth of Vigna unguiculata. They reported a significant improvement in percentage germination, plant height and root elongation.

\section{Conclusion}

The benefits of mushrooms are relatively economical because the mushrooms can be grown on a number of inexpensive agricultural or forest wastes such as rice straw, corn cobs and saw dust. The fungal inoculum can also be mass-produced by current simple techniques used to produce fungal spawn. In the quest, for economical and ecologically sound methods for environmental remediation, the use of mushrooms is a very good approach and solution. More intensive research needs to be carried out on the potentials and ecology of a large number of edible mushrooms.

\section{References}

[1]. Abulude F. O, Adeyeye E.I and Asaolu S. S (2004). Metal levels in mushrooms consumed in southern Nigeria, Advances in Food Science. 26(4): 155-158.

[2]. Adenipekun C. O and Fasidi I. O (2005). Degradationof selected agricultural wastes by Pleurotus tube-regium(fries) singer and Lentinus subnudus(Berk)-Nigerian edible mushrooms. Advance in Food Science. 27(2):61-64.

[3]. Akpoja E. O, Okhuoja J. A and Eliwer Heferere B. A (2005). Ethomycology and indigenous cases of mushrooms among the Binispeaking people of Nigeria: A case study

[4]. Aremu M O, Basuk, Gyan S. D, Goyal A, Bhowmik P. K and Datta Banik. S (2009). Proximate composition and functional properties of mushroom flours from Ganoderma spp, Omphalotus Olearius(DC) sing and Hebeloma mesphaeum(Pers) Quels used in Nassarawa State, Nigeria. Mal of Journal Nutrition, 15 (2): 233-241.

[5]. Grube B. J., E.T, England and Kao Y. C. (2001). White bottom mushroom phytochemicals inhibit arometase activity and breast cancer cell proliferation. Journal of Nutrition. 12:3288-3293.

[6]. Huder G. W (2000), Magical Mushrooms, Mischievous mold Princeton, New Jersey: Princeton University Press. p. 175, ISBN 0691-07016-4. Isildak O. I, Turkekul M. Elmastas M, and Tuzen M (2004). Analysis of heavy metal in some wild grown edible mushrooms form the middle black sea region. Turkey Food Chemistry86: 547-552.

[7]. Ita, B.N., G.A. Ebong, J.P Essien and S. I. Ednok (2008). Bioaccumulation potential of heavy metals incredible fungal sporocarps from the Niger Delta Region of Nigeria. Pakistan Journal of Nutrition. 7(1): 93-97.

[8]. Koyyalamudi S. R., Jeong S. C, Song C. H, Cho K, Y and Pang G (2009). Vitamin D2 for nation and bioavailability from Agaricus bisporus button mushrooms treated with ultraviolet irradiation. Journal of Agriculture and Food Chemistry. 57(8): 3351-5. Doi:10.1021/JF803908q 
[9]. Lentinan (2009). About herbs Memorial gloan kettering Cancer Center. Mussak R and Bechtold T (2009). Handbook of Natural Colorants New York: Wiley pp 183-200. ISBN 0-470-511 99-0

[10]. Okhuoya A. J, Isikhuemhen O. S and Evue G. A (1998). Pleurotus tuber-regium (fr) sing. The sclerotia and sporophore yield during cultivation on saw dust of different woody plants. International Journal of Mushroom Science2:41-46.

[11]. Sarfaraz K. W, Mir A. K, Muhammad A. K, Mushtaq A, Muhammed Z, Fazal-Ur-Rehman and Shazia S. (2009). Vegetables mentioned in the Holy Quran and Ahadith and their ethnomedical studies in Dera Ismail Khan N.W.F.P., Pakistan (http://Scialert.net/fulltext/?doi=pjn.2009.530. 538). Pakistan Journal of Nutrition8(5):530-538.

[12]. Smith J. E, Rowan N. J., and Sullivan R. (2002). Medicinal Mushrooms for cancer. Cancer Research UK. (http://sci.concer researcherchuk.org/labs/med_mush/med_mush.html)

[13]. Selvam K, Swaminathan K, Song MH, Chae KS (2002). Biological treatment of a pulp and paper industry effluent by Fomes lividusand Trametes versicolor. World J. Microbiol. Biotechnol. 18(6):523-526.

[14]. Stamets P (1999). Helping the Ecosystem through Mushroom cultivation. Fungi Perfecti. Mushrooms and the Ecosystem Ecosystem.http://www.fungi.com/mycotech/mycov.html.

[15]. Wikipedia (Accessed, 2011). Mushroom Wikipedia, thefree encyclopedia. Retrieved from http://en.wikipedia.org/w/index.php?title mushroom and oldid=456373633. Categories: fungi.

[16]. Emuh FN (2010). Mushroom as a purifier of crude oilpolluted soil. Inter. J. Sci. Nat. 1(2):127-132.

[17]. Sack U, Gunther T (1993). Metabolism of PAH by fungi and correction with extracellular enzymatic activities. J. Basic Microbiol. 33:269-277. Sasek V, Cajthaml T (2005). Mycoremediation. Current state and perspectives. Int. J. Med. Mushrooms 7(3):360-361.

[18]. Tanaka H, Itakura S, Enoki A (1999). Hydroxyl radical generation by an extracellular low- molecular-weight substance and phenol oxidase activities during wood degradation by the white-rotbasidiomycetes Trametes versicolor. J. Biotechnol. 75(1):57-70.

[19]. Zebulun OH, Isikhuemhen OS, Iyang H (2011). Decontamination of

[20]. anthracene-polluted soil through white rot fungus-induced biodegradation. Environmentalist 31:11-19. 